\title{
Success and failure in school mathematics: effects of instruction and school environment
}

\author{
Reusser, Kurt
}

\begin{abstract}
Given the stubborn phenomenon of many children's serious difficulties and failure in mathematical learning, the hypothesis of developmental delay, or neurocognitively based deficiency should be complemented by further explanantions of children's weaknesses and substandard performance in mathematics. One obvious explanantion is that schooling and instruction for low ability children and for children with special needs is often inadequate. The present contribution examines selected research on mathematics learning under a cognitive instructional (didactical) perspective. Constructivist learning theory, the rooting of meaningful learning in concrete modeling activities, the balancing of understanding and practice in mathematics instruction, diagnostic and adaptive teaching, computer-assisted instruction, and the role of nonmathematical stumbling-blocks are discussed as principles and factors of effective mathematics learning and teaching
\end{abstract}

DOI: https://doi.org/10.1007/s007870070006

Posted at the Zurich Open Repository and Archive, University of Zurich ZORA URL: https://doi.org/10.5167/uzh-156537

Journal Article

Published Version

Originally published at:

Reusser, Kurt (2000). Success and failure in school mathematics: effects of instruction and school environment. European Child Adolescent Psychiatry, 9(Suppl 2):S17-S26.

DOI: https://doi.org/10.1007/s007870070006 
K. Reusser

\begin{abstract}
Given the stubborn phenomenon of many children's serious difficulties and failure in mathematical learning, the hypothesis of developmental delay, or neurocognitively based deficiency should be complemented by
\end{abstract}

Kurt Reusser $(\square)$

Institute of Education

University of Zurich

Gloriastr. 18 a

8006 Zurich, Switzerland

E-mail: reusser@paed.unizh.ch

http://www.unizh.ch/paed

\section{Success and failure in school mathematics: effects of instruction and school environment}

further explanantions of children's weaknesses and substandard performance in mathematics. One obvious explanantion is that schooling and instruction for low ability children and for children with special needs is often inadequate. The present contribution examines selected research on mathematics learning under a cognitive instructional (didactical) perspective. Constructivist learning theory, the rooting of meaningful learning in concrete modeling activities, the balancing of understanding and practice in mathematics instruction, diagnostic and adaptive teaching, computer-assisted instruction, and the role of nonmathematical stumbling-blocks are discussed as principles and factors of effective mathematics learning and teaching.

Key words Mathematical learning mathematics teaching - mathematics education - mathematical problem solving - classroom culture in mathematics instruction - sense making in mathematics - mathematical learning difficulties - didactics of mathematical learning difficulties - elementary mathematics instruction

\section{Introduction}

Mathematics learning and instruction figure prominently in the concern of the public discourse on education. Given that mathematics pervades modern civilization, the life of a student who persistently performs poorly in mathematics achievement can become a nightmare. Sometimes, the suffering has a name developmental dyscalculia. However, compared to the widespread phenomena of failure in mathematics learning by students of all age and grade levels, only a few types of apparent weaknesses and learning disabilities related to arithmetics and mathematical problem solving might have a neurological basis at all. Research on its genetic or neuropsychological basis are still far from being clear-cut (14). The cognitive components (e.g., "fact retrieval", "counting", "conceptual knowledge", "number sense") underlying mathematical ability not only rely on the functioning of neurocognitive systems, but are also heavily sensitive to instructional and environmental factors.
Given the rich body of research literature on mathematics learning and teaching (see, e.g., $(15,21))$ there is convincing evidence that

- Most observed failures and substandard performance in mathematics learning are not due to genetic factors at all but to insufficient teaching-learning environments, i.e., to inadequate schooling;

- Even learning difficulties with a neuropsychological diagnosis (of deficiency or developmental delay of cognitive components) are substantially reinforced and shaped by environmental influences, e.g., insufficient measures taken by the instructional and educational support systems.

Mathematical learning difficulties, even if proven to have a genetic or hereditary component, do not appear "out of the blue" but manifest itself, as combinations of environmental and neurodevelopmental problems, in instructional and socio- 
cultural contexts $(14,32)$. There is a common "misunderstanding to think that genes determine outcomes in a hardwired, there-is-nothing-that-we-can-do-about-it way" (32, p. 235). Larger than the group of neurocognitively disabled children in ordinary mathematics classrooms is the group of the children whose motivational dispositions and attitudes toward doing mathematics, and whose self-concept of ability related to mathematical learning has been damaged (or are in danger of doing so) by the low quality of educational and instructional environments. The educational design of effective learning and teaching environments - or simply, good teaching - should, thus, be considered a key factor both in the prevention and remediation of a wide class of mathematical learning difficulties. According to a recent meta-analysis of treatment outcomes of intervention research on students with learning disabilities (46), effective teaching methods identified in the general literature on learning and instruction are also effective for disabled children.

The goal of this contribution is to present a view on the teaching and learning of mathematics that has emerged from theoretical and empirical research, such as studies on learning as a constructive, cumulative and meaningful activity embedded into sociocultural contexts. There is a consensus in current learning theory (not only mathematical) that the importance of domain-specific knowledge and skills, the orientation toward understanding, problem solving and social interaction are among the most critical dimensions with regard to the design of effective teaching-learning environments. This is considered to be valid not only for students of various grade levels but also of all levels of mathematical ability, including children with mathematical learning disabilities.

\section{A cognitive-constructivist perspective on learning and instruction}

The most basic idea in current learning theory is that learning is an active and constructive process. Even if treated in many schools as rather passive recipients of information, children are active individuals who genuinely construct and modify their mathematical knowledge and skills through interacting with the physical environment, materials, teachers and other children. Verbs such as observe, explore, express, describe, elaborate, justify, represent, re-arrange, paraphrase, investigate, cooperate, discuss, review, negotiate and predict can be used to convey this mindful involvement by children. According to radical forms of constructivism (16), students construct on their own/for themselves the meaning of mathematical concepts and practices through interaction with the physical world and during social interaction and dialogue, and develop conceptual and procedural schemata that are unique. ${ }^{1}$ Opposing all forms of direct instruction, radical constructivism, in some of its proposed didactic consequences, comes close to radical progressive education which goes along with an idealized, almost mythical view of the self-constructive nature of learning. Less radical and more pragmatic forms of knowledgebased constructivism $(2,33)$ emphasize the role of socially shared prior knowledge and of teacher guidance to the formation of concepts and skill structures. Knowledge-based constructivism acknowledges that both procedural (skill-related) and conceptual learning require extensive practice on a whole range of tasks and examples, and it also acknowledges the need for a balance in instruction between skill-orientation (forms of drill and practice) and orientation toward learning with understanding. Simply exposing children to (often enough) poorly designed (social) situations and materials, and telling them to (inter)actively construct mathematical meaning is not enough. Students will not construct, or discover in a few hours what has taken culture years or centuries to develop. Or, with regard to any elementary mathematical skill: there are merely slow constructive processes in which the elements of a simple procedure partly and gradually becomes integrated into a mastered skill. Only under intelligent support structures, where teachers act as structural and procedural role models, as domain experts, scaffolds and learning coachs - more generally, as impulse-givers and facilitators of learning - can (co-) constructive learning of nondisabled children as well as of children located in the lower segments of mathematical performance be expected to be productive. It is a common misconception that constructivist learning goes along with a deemphasis of practicing basic cognitive skills and with the fading of the role of the teacher. Given that learning is an active and constructive process, the role of teachers is to design discourse-oriented learning environments encouraging children to (inter-)actively explore, express, develop, discuss, and practice mathematical ideas. They need to be sensitive to children's curiosity and their physical and mental efforts of sense making, and be able to mediate the development of mathematical thinking of students.

${ }^{1}$ Epistemiological constructivism, which is rooted in the work of Immanuel Kant, was introduced into modern psychology by Jean Piaget (29). One of its fundamental assumptions is that no child and no learner can be forced by any teacher, or tool, to any insightful understanding of a concept, or to any intrinsic and deeper learning. According to Piaget, any developmental change as well as any knowledge building activity is building relationships ("mise en relation"), thus a genuine constructive activity that every child always has to do on his/her own, and that nobody ever can do for the child. 


\section{From concrete modeling to symbolic computation}

According to Piaget and Szeminska (31), the development of abstract conceptual structures, such as mathematical thinking, is rooted in infancy and in early childhood. Mathematical thinking only slowly emerges from informal acting and intuitive reasoning, including the use of ordinary language and qualitative world knowledge, a developmental pass which Piaget (30) framed as "abstraction à partir de l'action" or "reflective abstraction" (abstraction réfléchissante). To acquire the concepts of elementary mathematical operations means learning to focus on the protoquantitative aspects of goaldirected acting and real life situations. Children acting intelligently (i.e., in goal-directed, task- and context-specific ways) in everyday situations acquire a considerable amount of protomathematical knowledge with real objects by collecting, joining, taking-away, distributing them, before they enter school and master mathematical language. As Staub and Stern (44) point out:

"Long before children receive systematic instruction in school, they can compare sets at least qualitatively by stating which one is bigger: they can reason about increases and decreases of sets; and they possess a protoquantitative partwhole schema that allows them to understand that quantities can be composed of each other. As children integrate their protoquantitative reasoning with the separately developed competency to count objects, they begin to operate with quantitative schemata. Finally, given that children encounter situations that encourage participation in corresponding discourse, children also learn to reason about numbers and operators without immediate reference to actions and physical quantities. In discourse about numbers and there relations, numbers obtain the status of purely conceptual entities" (p. 70).

Mathematical operations are developmental derivatives of sensorimotor actions; they are "interiorized abstract actions" $(1,35)$. Concrete actions, expressed by verbs such as giving, getting, selling, or losing sets of objects are seen as bearing the abstract relational ideas that are inherent in elementary mathematical operations like adding, subtracting, multiplying and dividing. The responsibility of elementary teachers consists of building onto this existing protomathematical experience of children, i.e., to mediate the development from concrete physical modeling to progressively higher levels of abstraction. Skillful guidance of children from direct acting (including the studying of phenomena in the real world) ${ }^{2}$ to symbolic computation, requires expert teachers who know that children must learn to trust their own abilties of mathematical sense making, and that a premature rush to impose formal mathematical language is to be avoided. As experienced teachers know: swotting up on number facts is fast and doable for everyone, however, hardly productive, while learning by understanding needs time - and skillful scaffolding and mediation. Throughout the early years, teachers should give students widespread opportunities to develop, use, and practice their mathematical capacities by providing (or letting them find) intelligible forms of representation, and by letting them physically model, cooperatively discuss and reflectively think about situations. However, simply using materials in barely structured ways does not ensure understanding. The teacher's role is to make students become aware of the mathematical structures they are producing while physically modeling concrete situations, and to elicit students' thinking, communication, and reasoning (c.f. (26)).

\section{Learning with understanding and practice to mastery}

It is a widely accepted idea that students should learn mathematics with understanding, actively building new knowledge from experience and prior knowledge $(22,27)$. An increasingly less widely accepted idea is that student should practice to mastery what they might be able to understand. The educational philosophy of radical constructivism currently shatters the beliefs of many mathematics teachers about the pedagogical value of drill and practice, that is, of fostering basic skills, such as immediate retrieval of number facts and the fluent execution of elementary mathematical operations. From a point of view of knowledge-based cognitive constructivism, which goes along with the appreciation for prior knowledge and basic skills, meaning construction with understanding and automaticity in the execution of procedures are just two sides of a single coin. According to Hiebert and Carpenter (22), understanding not only enhances transfer but also promotes remembering, as by reducing the amount of pieces ("chunks") of knowledge that must be held at the same time in short-term memory.

Let's take number sense - understanding numbers, recognizing the relative magnitude of numbers and the effect of operating on numbers, ways of representing numbers, multiple relationships among numbers and operation properties, number systems $(27,43)$ - as an example. Number sense or flexibility in thinking about numbers and operations refers to a well-organized network of numerical knowledge allowing numbers to be used and represented in multiple ways, including relating them to each other, composing and decomposing them, or embedding them in various contexts of mathematical operations and problem solving. ${ }^{3}$ For example, the numbers 4 ,

${ }^{2}$ C.f. also the framework of Realistic Methematics Education $(11,47)$. In this perspective, basic mathematics is in the first place a human activity connected to real life situations. Mathematical learning starts out from the modeling of situations and phenomena in the real world. Higher levels of conceptual abstraction are progressively acquired through cooperative interactive, and reflective learning. 
5 and 9 may appear in contexts where the problem is to add 4 +5 , or to subtract either $9-4$, or $9-5$. While some students solve the small arithmetic problems by just retrieving "number facts" from memory, or by counting and other informal calculational procedures, most students, hopefully, will be able to derive in an inventive process the unknown from already known facts, i.e., to understand the multiple relationships of numbers and operations. In developing the meanings of numbers and operations and how they relate to each other, children should encounter the properties of these mathematical entities that constitute the basic elements of mathematical knowledge. Learning to calculate is more than memorizing and retrieving number facts; even learning the most trivial arithmetical knowledge means to construct, elaborate and flexibly mentally walk through networks of numerical connections. The more structured and interconnected the networks, the fewer pieces of knowledge that need to be retrieved separately. Moreover, accessing single parts of the network may lead to the retrieval of the whole network. That is, transparently structured and tightly interconnected arithmetic networks not only are beneficial for deep conceptual understanding but also, by reducing the processing demands, for remembering and the fast execution of subroutines.

Children in their first two years of school need to understand how numbers relate to each other, and how mathematical operations (beyond the mere manipulation of numbers) represent relationships. Moreover, they need to develop a solid understanding of the base-ten numeration system and placevalue concepts $(13,27)$. It needs many instructional experiences and a lot of practice to develop the sense for numerosity and operational relationship which allows, on demand, children to go back and forth between conceptual understanding and fact memorization, and which ensures - beyond learning in a rote manner - both transferable and persistent mathematical knowledge.

\section{Adaptivity and empathy in teaching}

"The success of education depends on adapting teaching to individual differences among learners" (7, 42). Even if theories about instructional adaptation have been vague, and no systematic procedures have been available to solve this profound and pervasive problem, there is enough evidence supporting the hypothesis that macro- and microadaptive, individualized teaching is crucial to the success and failure of children - especially of low ability children or children with special needs - in school learning. Microadaptation refers to the moment-to-moment decisions of teachers aiming at tailoring instruction to the needs of different learners. As research indicates, expert teachers define themselves in part as experts with regard to their craft to reach individual students, i.e., to make their teaching responsive to individual differences (17). There are many ways effective teachers can make both their thinking and their behavior responsive to differences in students. According to Corno and Snow (7, p. 613f) teachers can qualitatively or quantitatively vary and adjust

- The organizational structures of the class - by manipulating the groups, the learning centers, the reward structures so long as grouping is short-term and not stigmatic;

- The manner in which information is presented in recitation ${ }^{4}$ - prompting students to organize lesson materials for themselves, or to provide their own examples of principles learned; or to use self-monitoring or self-reinforcing techniques and other aspects of self-regulation;

- The materials they chose to present information or to guide problem solving - their examples, analogies, and points of emphasis, review, and summary;

- The support materials they use - aides, media, and so forth, and the level and form of question asked (e.g., higher order questions that prompt students to go beyond information given in their answers);

- Reinforcement given for correct responses, the level of explanantion provided for incorrect responses, the push to take a second try;

- The types of prompting student questions to aid in diagnosis;

- Instructional processes to individual student responses but also to their growing conception of student cognition and motivation with respect to learning the tasks at hand;

- The amount of time spent with different students on the same problem;

- The amount of time students are encouraged to spend with other students or media;

- The number of questions asked to assess learning;

- The amount of feedback given for particular responses, and pacing;

With regard to low performing students in mathematics, adaptive teaching is generally associated with remedial instruction provided to individual students depending on their specific

${ }^{3}$ In the Curriculum and Evaluation Standards for School Mathematics (NCTM 1989), number sense is described as "an intuition about numbers that is drawn from all the varied meanings of number" (p. 39, quoted from Sowder (43), p. 381).

${ }^{4}$ The term "recitation" refers to a basic pattern of repeated instructional steps that can be observed in almost all teaching. The three teaching "moves" corresponding to the pattern are: (i) "structuring" (explanantory presentation of information), (ii) "soliciting" (diagnostic monitoring and evaluating student learning, (iii) "reacting" (providing adaptive feedback to student responses) (4; quoted from Corno \& Snow (7)). 
weaknesses. An important prerequisite for remedial learning and instruction is diagnostic monitoring resulting in a cognitive instructional analysis of specific difficulties and problems of an individual learner. Teachers should attune to each student's strengths and weaknesses, styles of problem solving, and relevant prior knowledge in order to obtain a fine-grained profile of the general and task-specific problems, conceptual misunderstandings and procedural deficits before selecting and/or designing appropriate alternative materials for remediation. That is, effective teaching requires understanding what individual students know what they still need to learn and what their problems and difficulties are.

Adapting teaching should, moreover, include the study of student errors while solving mathematical tasks. Errors ought to be treated as a diagnostic and as a windows into their mathematical thinking. A pedagogical task of teachers is to establish a "positive error culture" (see (3)), i.e., errors should less be seen as indicators of failure - often enough negatively feeding back to motivation and self-concepts of students ${ }^{5}-$ but as learning opportunities and as challanges to clarify conceptual misconceptions. Most errors that appear consistently and that evolve over a long period of learning have their history in the child's prior systems of knowledge and meaning. Overviews on a whole range of diagnostic instruments for mathematicsspecific learning difficulties including error profiles of students, as well as on remedial strategies, measures and materials that are designed on a cognitive psychological basis (content and process analysis) can be found in Grissemann (19, 20, $25)$. Long-term cognitive instructional monitoring and adaptive, task-specific remedial teaching which are responsive to the difficulties of individual learners should be seen not only as the backbone of professional teaching but also as a significant prevention of more severe types of disorders in arithmetic skills.

\section{Learning and teaching with computer tools}

A type of instruction that holds the promise to provide learnersensitive microadaptation more immediately and more systematically than do classroom teachers is computer-assisted instruction. Even if the high expectations that were raised with

\footnotetext{
${ }^{5}$ Research (c.f. $\left.(10,26)\right)$ has persistently shown the problematic influence of motivational patterns and non-cognitive apitudes - low interest, low self-efficacy and self-concept, high anxiety, an external locus of control, a tendency to internalize failure - on performance and achievement. Cognitive-behavioral intervention, thus, should extend to non-cognitive factors of performance.
}

the advent of intelligent tutoring systems in the 1980s have not been fulfilled, computer-based learning programs can be designed to make moment-to-moment microadaptations in the sense that subsequent information is selected conditioned on different learners' responses to previously presented information $(7,23)$. There are many programs available, nowadays, most of them drill-and-practice programs, that can be used to acquire and practice elementary mathematical operations. Typical drill-and-practice programs provide children with sequences of tasks and immediate feedback about the correctness of responses; some programs even with adaptive help and verbal comments. There is evidence of a moderate effectiveness of computer-assisted learning with regard to motivational, attitudenal, and performance measures (for a metaanalysis see (24)). Given the fragility of the self-concept of students with a negative learning history and the accompanying side-effects of suffering teacher-student relationships, computer programs behaving entirely unauthoritarian, being endlessly patient, not getting tired of poor responding from students, and never distributing negative moral sanctions and reinforcements, may be beneficial especially to slow learners or to children with negative motivational patterns. Technology may also help students with special needs to develop number sense. For example, students having difficulties with placevalue concepts can - cooperatively or together with the teacher - observe values displayed by a computer program, or on a calculator and focus on (discuss, share) which digits (units digit, tens digit) are changing if certain numbers are added or subtracted, or if a target number must be reached (27; p. 81f).

\section{"From words to situations to equations": non-mathematical stumbling-blocks of mathematical learning}

Word problems are used at critical points of childrens' school careers to assess situated mathematical problem solving. As textual entities, word problems consist of two interwoven semiotic layers: a story-like description of some event in the real world, and a latent web of mathematical relations. Both textual worlds are related by a problem question defining a variable, the value of which has to be determined. Understanding and solving even of simple mathematical word problems has been proven to be a complex and highly inferential process that requires skillfull interaction of at least three kinds of knowledge: linguistic, situational (real world semantic), and mathematical; and it entails transforming natural-language texts into some canonical form of mathematical expression, e.g., an equation, or in a form of representation which on an elementary level allows for the application of counting strategies. In this process of transformation, the underlying logicomathematical deep structure of a word problem is only one 
Table 1 Percentage of solved problems by 2 nd graders, either using manipulatives (blocks) or not (37)

without blocks

How many marbles does Joe have now?

P2. Joe had some marbles. Then he gave five marbles to Tom.

Now Joe has three marbles. How many marbles did Joe have in the beginning?

P3. Joe has three marbles. Tom has five marbles. How many marbles do they have altogether?

P4. Joe and Tom have eight marbles altogether. Joe has three marbles. How many marbles does Tom have?

P5. Joe has eight marbles. Tom has five marbles. How many marbles does Joe have more than Tom?

P6. Joe has eight marbles. He has five more marbles than Tom. How many marbles does Tom have?

using blocks

100

100

65

70

100

55

65

35
100

70

85

65 constraining factor for arriving at the right calculation strategies. As numerous studies have shown (c.f. (45)), factors other than arithmetical skill are a major source of difficulty with word problems. Two groups of nonmathematical factors have been shown to heavily influence problem difficulty: semantic factors and wording factors (ibid.). Semantic factors refer to the nonmathematical action or situation structure underlying word problems. As studies show, problem difficulty varies with the type of familiar or unfamiliar, intuitively meaningful or more abstract, realistic or artificial, static or dynamic situation described in a word problem. Wording factors refer to the linguistic (lexical, syntactic) surface structure, or presentational structure of tasks. Even minor variations in the use of specific linguistic means may have a significant impact on problem difficulty that cannot be explained by the logicomathematical structures (34).

As an example, consider the problems in Table 1. They have some similarities and some differences both on the surface level of wording (presentational structure) and on the deep structural level (semantic and logico-mathematical structure), but are solvable by simple arithmetic operations (adding, substracting). P1 through P3, e.g., may be solved by adding 3 and 5. Yet the semantics of the three problems are quite different. The first and the second involve joining and separation, i.e., some literal action of change, in which a portion of objects is added to or removed from a set, and the task is to discover what the resulting set $(\mathrm{P} 1)$ or the initial set $(\mathrm{P} 2)$ is, or was, respectively. P3 is semantically different, involving part-whole relations. Here the task is to use information on the two subsets to obtain the number of the whole. Similar observations can be made with P4-P6 that may be solved by subtracting 5 from 8 . Yet the conceptual strucures of the three problems again are different. While P4 is semantically similar to P3 (even if because of the changed location of the unknown - leading to a different formal arithmetic operation), P5 and P6 constitute a third type ${ }^{6}$ of conceptual deep structure, requiring the identification of a difference set (P5) or the reference set (P6) in a compare situation.
Despite the fact that the formal solution methods for P1-P3 (adding) and P4-P6 (subtracting) are identical - and trivial, by connecting merely two numbers - their underlying deep structures differ radically. Moreover, there are wording factors which contribute to problem difficulty. It is known that young children have particular difficulties in understanding words that refer to quantity, such as some, more or more than, or to time concepts, such as temporal adverbs, or the expression of tense $(8,45)$ - a fact that also relates to what is known about language development in children (6).

Finally, it should be noted that solving the same (and many other) types of problems with and without manipulatives makes a significant difference in difficulty. This is important for the instruction of disabled and nondisabled children who have difficulties in selecting and integrating relevant pieces of problem information, in building adequate mental representations of actions and problem episodes, or in storing intermediate results in short-term memory. One of the advantages in solving mathematical word problems with manipulatives is that external aides, as blocks, allow for the concrete modeling of problem situations and thus reduce the load of working memory.

Successful mathematization in solving word problems includes the construction of several interrelated mental representations, each of which being able to become a major determinant of children's difficulties: a textbase as a propositional representation of the linguistic input, an episodic situation model as a qualitative representation of the nonmathematical "real-life" content, a mathematical problem model as the abstract gist of the situation, and an equation (35). It is well

${ }^{6}$ The three types of problems represented in Table 1 are CHANGE (P1-P2), COMBINE (P3-P4), and COMPARE problems (P5-P6). The problem types differ in their situation semantics and in the location of the unknown (c.f. (36)). 
known that students who are severely lacking in all types of relevent knowledge and skills - reading and language comprehension skills, real world knowledge, diagramming and problem representation skills, metacognitive organization of problem solving, arithmetic-fact retrievel and counting skills - are not able to easily go through these necessary steps of representation, and adopt many types of coping strategies that bypass the logic of mathematical sense-making activities. For example, there are many students who just plug numbers into some equations or perform various kinds of "magic" number work. Since students with learning disabilities, including poor reading comprehension, belong to this group, they need the guidance of effective pedagogical settings.

An important requirement is that problems are presented in contexts that are meaningful to the child. This implies that, to a certain degree, other types of problems and contexts - more familiar and realistic ones than the impoverished diet that can be found in many textbooks - are selected or created by the teacher. Furthermore, in order to improve the problem-solving skills of slow learners and of children with learning disabilities, instruction should help those children to analyze, reflect - and, above all, to practice - the overall required sequences of steps in understanding and solving different types of word problems, including the reflective discussion of errors. Steps that should be included in the (remedial) teaching of mathematical problem solving are

- Careful reading of the problem text, and putting what is read into a child's own language, allowing them to connect its semantic content with their everyday and intuitive concepts and experience;

- Building an episodic situation model, i.e., a concrete and vivid representation of the nonmathematical content of the problem, of what the text is about;

- Focusing on critical words and phrases carrying information with regard to the underlying deep structure of the problem;

- Stating the mathematical goal associated with the specific problem, by analyzing the explicit question (or by generating one if no question is given);

- Constructing a reduced and gradually abstract mathematical understanding of the problem, including the use of drawings and diagrams;

- Mapping the abstract problem model onto a formalized canonical notation, such as an equation, or onto the application of arithmetic procedures.

\section{Mathematical sense making and the culture of schooling}

Mathematical behavior is shaped by the instructional context and the social and historical culture of schooling in which it takes place. In quite contrast to an idealistic understanding of classroom problem solving as insightfully following the factual logic of things, or the inner requirements of situations (48), there is a growing body of research showing that schooling also follows a social or contextual logic. There is ample evidence showing that learning in many mathematics classrooms is hardly optimally directed toward mathematical modeling or deep conceptual understanding. Many students conceptualize and solve mathematical problems in a rather rote manner, without going back to a level where they are trying to understand its mathematical and/or real world meaning. Among the evidence documenting students' failure in mathematical understanding are studies showing that, e.g., students readily "solve" unsolvable, even absurd, problems if presented in ordinary classroom contexts $(34,40)$, almost never ask themselves if a problem given to them is solvable (47), and frequently use superficial key word strategies in order to solve a problem (28).

Consider the following nonsense problem from a French source that was given to 76 first and second graders in a school setting (34; p. 324f):

- There are 26 sheep and 10 goats on a ship. How old is the captain?

Although being clearly absurd, more than three of four students produced a numerical answer to it. A similar problem goes as follows: "There are 125 sheep and 5 dogs in a flock. How old is the shepherd?" The following quote from a fourth grade student working the problem out loud speaks for itself:

- $125+5=130 \ldots$ this is too big, and $125-5=120$ is still too big ... while $125 / 5=25 \ldots$ that works ... I think the shepherd is 25 years old.

Reusser and Stebler (37) asked in two studies 180 Swiss students from $4^{\text {th }} / 5^{\text {th }}$, and from the $7^{\text {th }}$ grade level to work a list of ten ill-defined or unsovable problems. Examples were

- Steve has bought 4 planks of $2.5 \mathrm{~m}$ each. How many planks of $1 \mathrm{~m}$ can he get out of these planks?

- John's best time to run $100 \mathrm{~m}$ is $17 \mathrm{sec}$. How long will it take him to run $1 \mathrm{~km}$ ?

- A man wants a rope long enough to strech between two poles $12 \mathrm{~m}$ apart, but he has only pieces of rope each $1.5 \mathrm{~m}$ long. How many of these pieces would he need to tie together to make the rope long enough to strech between the poles?

More than $90 \%$ of the students' responses to the problems were numerical solutions. Only $18 \%$ of the $4^{\text {th }} / 5^{\text {th }}$ graders' and $42 \%$ of the $7^{\text {th }}$ graders' answers reflected the inclusion of some real-world knowledge into the solving of the problems. That 
is, most students from $4^{\text {th }}$ and $5^{\text {th }}$ grade and still a majority of $7^{\text {th }}$ grade students gave answers that simply do not make sense if one takes the problem statements seriously. Asking the $4^{\text {th }}$ and $5^{\text {th }}$ grade students afterwards to comment on the problems and to evaluate the correctness of their solutions, revealed the result that most of the students reported that they understood most of the problems well, that they did not have difficulties solving them, and that they were not wondering whether the tasks were solvable or not. Very few students spontaneously expressed the opinion that one or several problems were the least bit out of the ordinary.

Note that the reported behavior stems from nondisabled students from regular classrooms. ${ }^{7}$ If nondisabled students apparently disregard considerations of reality and fail to to note any ill-definedness, unsolvability, or meaninglessness of simple problem statements (see $(34,40)$, for further examples), one can easily imagine what the difficulties of disabled students are or might be, if being left with the solving of irregular - and regular (!) - mathematical problems.

What can be learned from this research on "non-realistic mathematical behavior"? The first lesson is that the documented "suspension of sense-making is anything but anomalous. It is, rather an all-too-frequent occurrence ... that develops in school, as a result of schooling" $(41$, p. $316 \mathrm{f}$, commenting on the empirical findings of Reusser 34). That is, the explanantion of this kind of mindless behavior should not be sought in some cognitive deficit of the children but in the web of conventions and everyday practices of the mathematics classroom $(18,34,41)$. The second lesson is instructional (didactical) support of mathematical modeling. Realistic mathematical modeling that is based on understanding the meaning of mathematical tasks and situations is a highly demanding, however, in almost any respect /aspect of difficulty, clearly underestimated activity. In a subsequent study,

\footnotetext{
${ }^{7}$ The whole range of student ability and school types were included into the study.

${ }^{8}$ C.f. also Freudenthal (11; p. 70): "In the textbook context each problem has one and only one solution: There is no access for reality, with its unsolvable and multiply solvable problems. The pupil is supposed to discover the pseudo-isomorphisms envisaged by the textbook author and to solve problems, which look as though they were tied to reality, by means of these pseudo-isomorphisms. Wouldn't it be worthwhile investigating whether and how this didactic breeds an antimathematical attitude and why the children's immunity against this mental deformation is so varied."
}

Reusser and Stebler (38) transformed five out of the ten problematic (equivocal, unsolvable) tasks that were used in their previous study (37) - including the three above mentioned problems - into hands-on performance tasks. That is, the still verbally formulated problems were, in addition, presented as practical tasks, accompanied by appropriate concrete material (as real planks with saw and meter stick, stop watch, rope, scissors, etc.). Instead of merely solving the problems with paper and pencil, two classes of $6^{\text {th }}$ and $7^{\text {th }}$ grade students were instructed to do a hands-on-performance of each tasks - with the result that realistic reactions (explicitely noticing that and/or why the problems were unsolvable or equivocal) almost tripled compared to a baseline (paper and pencil) collected from the same students at the beginning of the study. The study shows that changing the modeling perspective - from a merely verbal to an interactive presentation of tasks - immediately had a significant impact on performance. The third lesson is to change the socio-mathematical norms within the classroom community (18), by the use of more realistic problems ${ }^{8}$, and by varying instructional methods and socio-cognitive support structures including, e.g., small-group interactions, wholeclass discussions, and various forms of communicative scaffolding and coaching. It implies a critical stance towards any shallow practices of mathematization in classrooms, and it includes breaking with some "tacit sets of beliefs and values that are perpetuated by the day-to-day practices and rituals" $(40 ;$ p. 82$)$ of schooling over a considerable period of time - practices that apparently lead to undesirable effects of mathematical learning and socialization.

Schooling and school culture are not the only influence on children's academic behavior. A complementary, even more basic determinant of the socialization of strategies, habits, beliefs and values related to learning in general as well as to subject-matter-related learning, is family culture. What expectations for mathematical performance parents have, what their relative emphasis on ability versus effort is, in what direct and indirect ways school learning is cognitively stimulated and assisted by the home environment, greatly affects children's beliefs, attitudes, and behavior $(12,14)$. Thus, to intervene, as a didactician, as a cognitive instructional psychologist, or as a medical person in the case of serious mathematical learning difficulties, requires one to study the individual socio-systemic context of learning and instruction. The learning of basic mathematical skills, its long-term success - or failure - is the least shaped by our genes alone, but by the systemic factors of educational and instructional culture, and by our ability to create supportive learning environments for all children. 


\section{References}

1. Aebli H (1980) Denken. Das Ordnen des Tuns (Thinking - Bringing order into action). Zwei Bände. Stuttgart: Klett

2. Aebli H (1987) Mental development: Construction in a cultural context. In: Inhelder B, de Caprona D, Cornu-Wells A (eds) Piaget Today. Hillsdale, NJ: Erlbaum, pp 217-232

3. Althof W (1999) (ed) Fehlerwelten. Vom Fehlermachen und Lernen aus Fehlern. Opladen: Leske + Budrich

4. Bellack AA, Kliebard HM, Hyman RT, Smith FL (1966) The Language of the Classroom. New York: Teachers College Press

5. Bishop AJ (1996) (ed) International Handbook of Mathematics Education. Dordrecht: Kluwer

6. Clark HH, Clark E (1977) Psychology and Language. New York: Harcourt, Brace, Yovanovich

7. Corno L, Snow RE (1986) Adapting teaching to individual difference among learners. In: Wittrock MC (ed) Handbook of Research on Teaching. New York: Macmillan, pp 605-629

8. Cummins D, Kintsch W, Reusser K, Weimer R (1988) The role of understanding in solving word problems. Cognitive Psychology 20: 405-438

9. De Corte E, Verschaffel L, Greer B (1996) Mathematics, learning, and Instruction of. In: De Corte E, Weinert FE (eds) International Encyclopedia of Developmental and Instructional Psychology. Oxford: Elsevier, pp 535-538

10. Dweck CS (1986) Motivational processes affecting learning. American Psychologist, 41 (10): 1040-1048

11. Freudenthal H (1991) Revisiting Mathematics Education. Dordrecht: Kluwer

12. Fuligni AJ, Stevenson HW (1996) Home environment and school learning. In: De Corte E, Weinert FE (eds) International Encyclopedia of Developmental and Instructional Psychology. Oxford: Elsevier, pp 597-601

13. Fuson KC, Wearne D, Hiebert JC, Murray HG, Alwyn OI, Carpenter TP, Fennema E (1997) Children's conceptual structures for multidigit numbers and methods of multidigit addition and subtraction. Journal for Research in Mathematics Education 28: $130-162$

14. Geary DC (1994) Children's Mathematical Development. Research and Practical Applications. Washington, DC: American Psychological Association
15. Ginsburg HP, Klein A, Starkey P (1998) The development of children's mathematical thinking: Connecting research with practice. In: Damon W, Siegel IE, Renninger KA (eds) Handbook of Child Psychology. Volume 4: Child Psychology in Practice. New York: Wiley, pp 401-476

16. Glasersfeld E von (1995) Radical Constructivism. A Way of Knowing and Learning. London: The Falmer Press

17. Good TL, Grouws D (1979) The Missouri Mathematics Effectiveness Project: an experimental study in fourth grade classrooms. Journal of Educational Psychology 71: $355-362$

18. Greer B (1997) Modelling reality in mathematics classrooms: the case of word problems. Learning and Instruction 7 (4): 293-307

19. Grissemann H (1996) Dyskalkulie heute. Bern: Huber

20. Grissemann H, Weber A (1993) Grundlagen und Praxis der Diskalkulietherapie. Bern: Huber

21. Grouws DA (1992) (ed) Handbook of Research on Mathematics Teaching and Learning. New York, Oxford: Macmillan

22. Hiebert J, Carpenter TP (1992) Learning and teaching with understanding. In: Grouws DA (ed) Handbook of Research on Mathematics Teaching and Learning. New York, Oxford: Macmillan, pp 65-97

23. Kaput JJ (1992) Technology and mathematics education. In: Grouws DA (ed) Handbook of Research on Mathematics Teaching and Learning. New York, Oxford: Macmillan, pp 515-556

24. Kulik JA (1994) Meta-analytic studies of findings on computer-based instruction. In: Baker EL, O'Neil HF (eds) Technology Assessment in Education and Training. Hillsdale, NJ: Erlbaum, pp 9-33

25. Lorenz HJ, Radatz H (1993) Handbuch des Förderns im Mathematikunterricht. Hannover, Schrödel

26. McLeod DB (1992) Research on affect in mathematics education: a reconceptualization. In: Grouws DA (ed) Handbook of Research on Mathematics Teaching and Learning. New York, Oxford: Macmillan, pp 575-596

27. National Council of Teachers of Mathematics (2000) Principles and Standards for School Mathematics. Reston, VA: The National Council of Teachers of Mathematics

28. Nesher P, Teubal E (1975) Verbal cues as interfering factors in verbal problem solving. Educational Studies in Mathematics 6: $41-51$
29. Piaget J (1950) Introduction à l'épistémologie génétique. Paris: Presses Universitaires de France

30. Piaget J (1970) Genetic Epistemology. New York: Columbia University

31. Piaget J, Szeminska A (1941) La genèse du nombre chez l'enfant. Neuchâtel: Delachaux et Niestlé

32. Plomin R (1999) Behavioral genetics. In: Bennett M (ed) Developmental Psychology. Achievements and Prospects. London: Psychology Press, pp 231-252

33. Resnick LB, Hall MW (1998) Learning organizations for sustainable educational reform. Daedalus 127 (4): 89-118

34. Reusser K (1988) Problem solving beyond the logic of things: contextual effects on understanding and solving word problems. Instructional Science 17: 309-338

35. Reusser K (1990) From text to situation to equation: cognitive simulation of understanding and solving mathematical word problems. In: Mandl H, De Corte E, Bennett N, Friedrich HF (eds) Learning and Instruction in an International Context. Vol. II. New York: Pergamon Press, pp 477-498

36. Reusser K (1992) Kognitive Modellierung von Text-, Situations- und mathematischem Verständnis beim Lösen von Textaufgaben. In: Reiss K, Reiss M, Spandl H (Hrsg) Maschinelles Lernen. Modellierung von Lernen mit Maschinen. Berlin, Springer

37. Reusser K, Stebler R (1997) Every word problem has a solution - the social rationality of mathematical modeling in schools Learning and Instruction 7 (4): 309-327

38. Reusser K, Stebler R (1997) Realistic mathematical modelling through the solving of performance tasks. Paper presented at the 7 th European Conference for Research on Learning and Instruction (EARLI), Athens, Greece. University of Zurich, Institute of Education

39. Riley MS, Greeno JG (1988) Developmental analysis of understanding language about quantities and of solving problems. Cognition and Instruction 5: 49-101

40. Schoenfeld AH (1989) Problem solving in context(s). In: Charles RI, Silver EA (eds) The Teaching and Assessing of Mathematical Problem Solving. Hillsdale, NJ: Erlbaum, pp 82-92

41. Schoenfeld AH (1991) On mathematics as sense-making: an informal attack on the unfortunate divorce of formal and informal mathematics. In: Voss JF, Perkins DN, Segal JW (eds) Informal Reasoning and Education. Hillsdale, NJ: Erlbaum, pp 311-343 
42. Snow RE (1996) Individual differences, learning, and instruction. In: De Corte E, Weinert FE (eds) International Encyclopedia of Developmental and Instructional Psychology. Oxford: Elsevier, pp 649-660

43. Sowder J (1992) Estimation and number sense. In: Grouws DA (ed) Handbook of Research on Mathematics Teaching and Learning. New York, Oxford: Macmillan, pp 371-389
44. Staub FC, Stern E (1997) Abstract reasoning with mathematical constructs. International Journal of Educational Research 27 (1): 63-75

45. Staub FC, Reusser K (1995) The role of presentational structures in understanding and solving mathematical word problems. In: Weaver CA, Mannes S, Fletcher CR (eds) Discourse Comprehension. Essays in Honor of Walter Kintsch. Hillsdale, NJ: Lawrence Erlbaum, pp 285-305
46. Swanson HL, Hoskyn M (1998) Experimental intervention research on students with learning disabilities: a meta-analysis of treatment outcomes. Review of Educational Research 68 (3): 277-321

47. Treffers A (1987) Three dimensions: A Model of Goal and Theory Description in Mathematics Instruction - The Wiskobas Project. Dordrecht: Reidel

48. Wertheimer M (1945) Productive Thinking (enlarged edition, 1982). Chicago: University of Chicago Press 